appeared I proceeded to examine them as carefully as possible, in order to see whether there were any male organs concealed either within or in their neighbourhood, but I searched in vain. In March 1883 the plants had covered the whole space allotted to them, and were then cut down. Branch after branch was once more submitted to the closest inspection, and the existing fruits, numbering 20 , were collected. Of these 20 fruits I examined 5, and found that 3 had perfect embryos ; Io were sown in pots, but only 3 germinated; the remainder of the crop I still have in my carpological collection.

The plants soon began to sprout anew, and were again carefully searched whenever time and weather would llow it. They were cut off in December I 884, giving a crop of 54 fruits, which were disposed of in the following manner:-Examined, Io, 7 having perfect embryos; sown, 20 ; germinated, 9 ; kept in salt solution, 24 .

The third period lasted till February 1886 . Both plants were very vigorous, and had produced a large number of flowers, so that I collected no fewer than 137 fruits, of which ro were examined ( 5 were good), 20 were sown, ( 8 germinated, the young plant being now about 6 inches high); the remainder will be sent to different botanical gardens within the tropics, in order that my experiments and observations may be repeated under the most favourable circumstances possible.

Since February the plants have grown a good deal; one is flowering and has already four fruits.

From the very outset of my observations I had noticed that these fruits appeared only on the thickened end of the flowering rachis, which is always the lowest part of the pendent inflorescence, as I have described in the first section of this paper. I cannot help thinking that this circumstance has something to do with the production of these fruits in general.

I must observe that the numbers 20,54 , and 137 of the fruits collected are not the total numbers of fruits produced by the plants in each period; for the earlier fruits fell off and got lost long before I gathered the crop. Whatever may have been this loss, it is certain that there was a constant and very notable increase of fruits. I am sorry I omitted counting all the flowering spikes at the time when the plant were cut down, so as to be able to compare their number with that of those bearing fruits, and to find out, at least approximately, whether both groups of numbers were reciprocally proportionate, or not so.

Be this as it may, there is no denying the fact that many female plants produced in three successive years an increasing number of fertile fruits without the operation of any fertilising pollen from a male flower.

The reader will remember that the nearest group of Disciphania is at a distance of about nine miles from Caracas. I am quite positive about this point, being well acquainted with the vegetation in the environs of the city. Now it is incredible that under such circumstances and in this species, which has neither showy flowers nor any perceptible smell, the pollination could have been effected by insects. It is furthermore certain that my plants of Disciphania are the only ones in Caracas, and that for this reason there is no specimen nearer to them than the few spontaneous ones which may grow in the ravine of Guarenas. ${ }^{1}$ And even if there had been any pollination from outside, how is it that plants, which are known to be extremely prolific under normal circumstances, should produce such very scanty crops, although grown under the most favourable conditions?

For these different reasons I hold that the possibility of pollination from a male plant is entirely out of the question, and may fairly be discarded

But it is likewise impossible that pollination could have taken place with material produced by the plants them-

${ }^{x}$ It is interesting that the second species of Disciphania (D. Lobata, Eichl.) appears likewise to be an exceedingly rare plant, as may be inferr from an observation of of Prof. Eichler's, in the article mentioned before. selves, as no rudimentary male flowers, nor auxiliary stamens, have been discovered on them during the most scrutinising search in three successive years; nor was there ever found one single grain of pollen on the hundreds of stigmas that were inspected in the course of this investigation. I well remembered Karsten's criticism of Alexander Braun's paper on parthenogenesis in Calebogyne, and was, accordingly, very scrupulous to establish beyond all question the absence of any pollen-producing organs. I am fully convinced that I should have found them, if any had really existed.

In another respect I was unable to arrive at a positive result. I could not make sure whether the embryo is developed as an outgrowth from a cell of the nucellus, as Strasburger has found in Colebogyne, or whether it is the development of an unfertilised oosphere. As, however, the former case appears to be always connected with polyembryony, which does not occur in the seeds of Disciphania, it seems to me more probable that in this plant we have an instance of the second case, or of true parthenogenesis, certainly not as the rule and normal modus of reproduction, but as an exception, and a very rare one, a kind of makeshift of nature, as it were, when the co-operation of the fertilising material cannot be realised.

In Prof. Weismann's essay, "The Continuity of the Germ-Plasma," there is a chapter on the nature of parthenogenesis, which abounds in suggestions which, in my opinion, throw much light on the case under consideration. I quote the following sentence from Prof. Moseley's abstract in NATURE, vol, xxxiii. p. I 57:- "If a special supply of nourishment reaches the germ-plasma, this increases in amount by growth, and thus obtains the mass requisite to start the ontogenetic process, with the result that parthenogenetical development takes place." Strasburger had already pointed out that an analogous result may be arrived at by specially favourable conditions in the supply of food, which counteracts the insufficiency of the germ-plasma. May we not suppose that something similar happens in Disciphania? Besides the herbaceous branches, the club-shaped rachis of the spicate inflorescences abound in proteids, and consequently there must be a specially abundant supply of food, which may have some particular influence on the growth of the ovary and its contents. And it is on those places we find precisely the fruits for which I claim a parthenogenetic origin. Caracas, June 7

A. ERNST

P.S.-Since the foregoing article was sent to England, I have made the following observation, which, I think, gives additional strength to my view as to the probable cause of parthenogenesis in the case under consideration. On one of my plants I had noticed two rather short inflorescences ( 4 and 5 centimetres long), with but 3 and 4 flowers respectively, but having a very much thickened, almost club-shaped, rachis, which measured at the apex nearly 3 millimetres each way, The idea struck me that on these spikes very likely some fruits would appear, and I marked them out for the sake of further inspection. $M y$ anticipations have been fully realised, as on each of the two there is now one ovary increasing in size, measuring already 3 millimetres by 2 , so that there is every reason to expect their final development.

At the same time I may mention that on the second plant, which has just begun to flower, I have found on one spike a tetramerous, and on another a pentamerons, female flower; both spikes were very small, and had only two flowers.

A. ERNST

Caracas, June 23

\section{OUR ENGLISH TEMPERATURES}

A PERIOD of warm weather, lasting for three weeks, set in over the whole of the United Kingdom about August 24, and continued until September 14, over nearly 
the whole country. Throughout this period there was no part of England in which the temperature was not above the average in each week, as shown by the returns issued by the Meteorological Office.

The persistent low temperature which preceded this warm weather, and which had so long continued, was described in NATURE for August I 2 (p. 341). This cool weather continued till August 23, when, fortunately, the conditions entirely changed, and a warm spell of exceptional length for either summer or early autumn set in. It is necessary to go back to February 1885 , eighteen months ago, before we find so long a period with the temperature above the average, and since that time there have not even been two weeks in succession which were warm generally over the whole country.

In recent years there has been but very little really settled warm weather during the three months July to September. Last year there was only one week, ending July 27 , which could in any way be termed warm generally over the country during the whole period of three months. In 1884 finer weather was experienced, and there were four consecutive weeks, ending August 25, with the temperature above the average over Great Britain ; there was also a period of three consecutive weeks, ending September 29, with warm weather, and two consecutive weeks ending July 14. In 1883 there was only one week, ending September 24 , in which the temperature was above the average over the whole of the British Islands, but there were other weeks during the three months in which the temperature was high in several districts ; there was, however, no continuous warm weather. In 1882 the week ending August I4 was the only instance with the temperature generally above the average, and in this period a deficiency was shown in the East of England. In $188 \mathrm{I}$ there was not a single week in the three months with the temperature generally above the average. In 1880 there were five consecutive weeks, ending September 13, with the temperature above the normal value, and warm weather was also enjoyed in the week ending September 27. In I 879 temperature was continuously low throughout the period, and the deficiency generally amounted to several degrees; there was not a single district over the whole of the United Kingdom with the temperature above the mean for a single week.

From this it is seen that during the last eight years there were but two years, 1880 and 1884 , which can in any way compare with this year for warm weather during the three months referred to, and in the remaining five years there was not a longer period than a single week with continuous warm weather.

The varying conditions with which warm weather occurs in England is exceedingly puzzling. This year it has accompanied weather of a cyclonic type, and has changed to cooler weather with the anticyclonic conditions which set in about September I4. To attempt an explanation of these conditions from observations for our own limited area, or even from the observations over Europe, would be but labour lost. For such an inquiry it is necessary to wait the issue of the synoptic charts for the northern hemisphere which are compiled by the United States Signal Service from the international synchronous meteorological observations. Doubtless a careful study of these will throw some light on the cause of the prolonged irregularities in the distribution of temperature.

CHAS. HARDING

\section{NOTES}

THE American Association at the Buffalo meeting unanimously passed a resolution expressing its gratification at hearing of Dr. Gould's proposed revival of the Astronomical Fournal, and its good wishes for its success.
Mr. G. T. PrIOR, B.A. of Magdalen College, Oxford, has been appointed an Assistant in the Department of Mineralogy in the British Museum, to fill the vacancy caused by the death of Dr. Flight. The two vacancies in the staff of the Zoological Department occasioned by the resignation of Mr. E. J. Miers on account of ill-health, and Mr. J. J. Quelch, appointed to the curatorship of the Demerara Museum, have been filled by the nomination after competitive examination of Mr. C. J. Gahan and Mr. Randolph Kirkpatrick. Mr. C. G. Crick has lately been appointed an additional assistant in the Department of Zoology.

WE regret to learn of the death of Dr. Clement Mansfield Ingleby, at the age of sixty-three years. The death is also announced of Admiral Bedford Pim.

WE regret to note the death of Prof. H. A. Bayne, Ph.D., of the Royal Military College, Kingston, Ontario, Canada. Dr. Bayne was a native of Nova Scotia. He graduated in Arts at Dalhousie College, Halifax, N.S., and afterwards spent five years in the special study of chemistry under Wiedemann at Leipzig, Bunsen at Heidelberg, and Dumas at Paris, taking his Doctor's degree at Heidelberg. Returning to his native land he first engaged in organising the Scientific Department of the Halifax High School, acting at the same time as Lecturer on Chemical Analysis at Dalhousie College. In 1879 he was appointed Professor of Chemistry at the Kingston Military College, which had just been founded. His work at Kingston was very onerous, and during the first few years of his professoriate he found little time for original research. At the last meeting of the Royal Society of Canada, of which he was a Fellow, he read a paper of practical value on chemical tests of the purity of silk. He had begun in Germany a series of experiments on the properties of certain of the rarer metals, in which he had been interested by Bunsen; and he hoped to continue them when leisure came. But he has been cut down at the very threshold of his work.

THE annual Exhibition of the Photographic Society was opened to the public on Monday.

NEWS of earthquakes and volcanic eruptions continues to arrive from all quarters. The North American earthquakes have not ceased. Three slight shocks were felt in Summerville on September 28, and at night several more occurred. Fram various parts of Central Germany, principally Thuringia, news arrives showing that in the night of the 27 th, or morning of the $28 \mathrm{th}$ ult., there was a series of more or less violent shocks of earthquake. At Gera and other places in Thuringia, the windows, doors, cupboards, and other movable articles of furniture, were violently agitated, shaking and rocking to and fro. A despatch received at New York on Tuesday from Mexico states that a high hill in the vicinity of Chimalapa has been completely riven in two by the action of subterranean forces. The volcano of Colima, in Mexico, is in a state of eruption for the third time within a year. Information has been received at Lerwick stating that two shocks of earthquake had been experienced at Baltasno, Unst, Shetlands, on Monday night. The first shock was felt at eleven, the other two hours later. Several people were roused from sleep by houses trembling and china rattling. Both shocks lasted several seconds, but no damage occurred to property. A telegram from Melbourne, October 5, states that a volcanic eruption has occurred in the island of Niapu, in the Tonga group. Two-thirds of the island are completely covered with volcanic dust. Mount Pabloff, 300 miles south of Kodiak, in Alaska, is in eruption.

MR. S. K. SEKryA writes from the Imperial University, Tokio, Japan :- "On July 23 quite a destructive earthquake visited Shinano, Echigo, and the neighbouring provinces, over- 